EP-24

\title{
Parenting stress: psychological condition of parents with children with cirrhosis of the liver
}

\author{
Ardela lga PRATIWI $^{*}$
}

Department of History, Universitas Gadjah Mada, Yogyakarta, Indonesia

Introduction: Cirrhosis of the liver is common in someone who has had liver damage for years, but it can also occur in children. The daily life of children with cirrhosis of the liver, both physical and psychosocial will be disrupted, so that the child becomes more dependent on their parents. However, often parents are not ready to accept the child's condition. This study was to describe the psychological condition of parents who care children with cirrhosis of the liver.

Methods: This study used electronic data base as a method by reviewing some articles published since 2007 to 2017.

Results: The results showed that the doctor's initial diagnosis of their child with liver cirrhosis was an initial problem that caused uncomfortable feelings in parents, such as shock, resistance, sadness, confusion, and anger. Parents feel responsible for their child's illness, which causes feelings of guilt and despair. The uncertainty of the child's condition or the potential that will happen to their child in the future is the biggest stressor for parents. The stress level will increase during transplant preparation and transplantation. In conditions of increase stress levels, not seldom create tension in the relationship between father and mother.

Conclusions: Parents who have children with cirrhosis of the liver faced more complex challenges than parents who have healthy children. They must prepare themselves for the doctor's diagnosis, progression of disease, need for treatment at an uncertain time, transplantation and also potential cure. In these conditions, having a good quality relationship between husband and wife is important to deal with the impact of problems with children with liver cirrhosis. In addition, parents need to seek social support from interdisciplinary health professionals for dealing with each stage of the stressor.

Key Words: Parents; Psychological condition; Chlidren with cirrhosis of the liver 